\title{
Acute environmental hypoxia induces LC3 lipidation in a genotype-dependent manner
}

\author{
Evi Masschelein,* Ruud Van Thienen,* Gommaar D'Hulst,* Peter Hespel,* \\ Martine Thomis, $^{\dagger}$ and Louise Deldicque*,1 \\ *Exercise Physiology Research Group and ${ }^{\dagger}$ Physical Activity, Sports, and Health Research Group, \\ Department of Kinesiology, KU Leuven, Leuven, Belgium
}

\begin{abstract}
Hypoxia-induced muscle wasting is a phenomenon often described with prolonged stays at high altitude, which has been attributed to altered protein metabolism. We hypothesized that acute normobaric hypoxia would induce a negative net protein balance by repressing anabolic and activating proteolytic signaling pathways at rest and postexercise and that those changes could be partially genetically determined. Eleven monozygotic twins participated in an experimental trial in normoxia and hypoxia $(10.7 \%$ $\mathrm{O}_{2}$ ). Muscle biopsy samples were obtained before and after a 20-min moderate cycling exercise. In hypoxia at rest, autophagic flux was increased, as indicated by an increased microtubule-associated protein 1 light chain 3 type II/I (LC3-II/I) ratio (+25\%) and LC3-II expression $(+60 \%)$ and decreased $\mathrm{p} 62$ /SQSTM1 expression $(-25 \% ; P<0.05)$, whereas exercise reversed those changes to a level similar to that with normoxia except for $\mathrm{p62/SQSTM1}$, which was further decreased $(P<0.05)$. Hypoxia also increased Bnip3 (+34\%) and MAFbx $(+18 \%)$ mRNA levels as well as REDD1 expression $(+439 \%)$ and AMP-activated protein kinase phosphorylation $(+22 \% ; P<0.05)$. Among the molecular responses to hypoxia and/or exercise, high monozygotic similarity was found for REDD1, LC3-II, and LC3-II/I $(P<0.05)$. Our results indicate that environmental hypoxia modulates protein metabolism at rest and after moderate exercise by primarily increasing markers of
\end{abstract}

Abbreviations: $\% \mathrm{SpO}_{2}$, arterial $\mathrm{O}_{2}$ saturation; 4E-BP1, eukaryotic initiation factor 4E-binding protein 1; AMPK, AMP-activated protein kinase; ANOVA, analysis of variance; ATG, autophagy-related gene; Bnip3, Bcl-2/adenovirus E1B 19-kDa protein-interacting protein 3; chr, chromosome; eEF2, eukaryotic elongation factor 2; eIF4F, eukaryotic initiation factor 4F; FOXO, forkhead box protein O; GAPDH, glyceraldehyde-3-phosphate dehydrogenase; LC3, microtubule-associated protein 1 light chain 3; HYP, hypoxia conditions $\left(F_{\mathrm{i}} \mathrm{O}_{2}=10.7 \%\right)$; ICC, intraclass correlation coefficient; MAFbx, muscle atrophy F box; MSTN, myostatin; mTOR, mammalian target of rapamycin; mTORC1, mammalian target of rapamycin complex 1; MuRF-1, muscle ring finger protein-1; MZ, monozygotic; NOR, normoxia conditions $\left(F_{\mathrm{i}} \mathrm{O}_{2}=20.9 \%\right)$; p62/SQSTM1, p62/sequestosome 1; PCNA, proliferating cell nuclear antigen; $\mathrm{PKB}$, protein kinase B; pre-ex, preexercise; post-ex, postexercise; REDD1, regulated in development and DNA damage responses 1; RPL4, ribosomal protein L4; S6K1, p70 ribosomal S6 kinase; TMB, tetramethylbenzidine; TOI, tissue oxygenation index; $V_{\mathrm{O}_{\max }}$, maximal oxygen consumption protein breakdown and, more specifically, markers of the autophagy-lysosomal system, with a modest genetic contribution.-Masschelein, E., Van Thienen, R., D'Hulst, G., Hespel, P., Thomis, M., Deldicque, L. Acute environmental hypoxia induces LC3 lipidation in a genotype-dependent manner. FASEB J. 28, 000-000 ( 2014). www.fasebj.org

Key Words: exercise $\cdot$ p62 $\cdot$ autophagy $\cdot$ monozygotic twin design

Throughout LIFE, MOst individuals experience episodes of tissue hypoxia, i.e., a state of lowered oxygen tension in tissues, and need to adapt to this environmental or pathological state. Tissue hypoxia can occur in healthy humans during a stay at high altitude (1), but various pathological conditions, such as chronic obstructive pulmonary disease (2), obstructive sleep apnea (3), and anemia (4), are also associated with tissue hypoxia. Whatever the origin of the hypoxia, physiological adaptations need to come into play to mitigate the reduced oxygen availability. For example, long-lasting hypoxia often leads to a negative regulation of protein metabolism and a loss of muscle mass. Epidemiological studies performed in natives of Tibetan, Ethiopian, and Andean highlands reported major population-specific differences in adaptive mechanisms to protect against hypoxia in their habitat (5-8). Those observations suggest that genetic variants are probably involved in the physiological adaptations to hypoxia. Although variability in cardiorespiratory responses to hypoxia has shown a clear genetic component $(9,10)$, little is known about the individual variability in muscle wasting responses related to hypoxia and their underlying regulatory pathways. Furthermore, the role of genetic variation in this variability has not been studied before.

The majority of the work dealing with the regulation of protein metabolism by hypoxia comes from in vitro studies. In vitro, it is commonly assumed that hypoxic

\footnotetext{
${ }^{1}$ Correspondence: Exercise Physiology Research Group, Department of Kinesiology, KU Leuven, Tervuursevest 101, B-3001 Leuven, Belgium. E-mail: louise.deldicque@faber. kuleuven.be

doi: 10.1096/fj.13-239863

This article includes supplemental data. Please visit http:// www. fasebj.org to obtain this information.
} 
conditions inhibit muscle protein synthesis (11). The latter is mainly controlled by the mammalian target of rapamycin complex 1 (mTORC1) pathway, which phosphorylates and activates 2 key regulators in the initiation step, the ribosomal protein S6 kinase 1 (S6K1) and the eukaryotic initiation factor 4E-binding protein 1 (4E-BP1), a repressor of the cap-binding eukaryotic initiation factor 4F (eIF4F) complex. During hypoxia, mTORC1 has been found to be inhibited by AMPactivated protein kinase (AMPK; ref. 12) and by the protein called regulated in development and DNA damage responses 1 (REDD1; ref. 13).

Unfortunately, those in vitro studies have mainly focused on the regulation of protein synthesis by hypoxia, whereas net protein balance is also determined by protein degradation. Recent animal studies give further insight into the anabolic and catabolic processes in response to hypoxic conditions in vivo (14-17). Although not corroborated by everyone (17), hypoxia seems to activate the ubiquitin-proteasome pathway as well as calpains $(14,15)$. The mRNA levels of the 2 muscle-specific ligases muscle ring finger protein-1 (MuRF-1) and muscle atrophy F box (MAFbx; ref. 15), which are up-regulated under conditions of muscle atrophy (18), and the levels of ubiquitinated proteins (14) are increased after several days of exposure to hypoxia in rat skeletal muscle.

Besides the ubiquitin-proteasome pathway and calpains, attention to a third proteolytic system, i.e., the autophagy-lysosomal pathway, is increasing (19, 20). In brief, in this system, double membrane vesicles that engulf portions of the cytoplasm, organelles, glycogen, and protein aggregates are generated. The autophagosomes formed bind to lysosomes, forming autolysosomes for degradation of their contents by lysosomal hydrolases. Autophagosome formation is under the control of some autophagy-related genes (ATGs) such as ATG5, ATG12, and ATG8 also known as microtubule-associated protein 1 light chain 3 (LC3; ref. 20). More recently, p62/sequestosome 1 (p62/SQSTM1) has been found to play a key role in delivering ubiquitinated proteins to autophagosomes (21). The ubiquitin-proteasome pathway and autophagy-lysosomal pathway are under the control of, among others, the forkhead box protein $\mathrm{O}$ (FoxO) transcription factors, which themselves are regulated by protein kinase $\mathrm{B}$ (PKB). Whereas autophagy clearly plays an important role in skeletal muscle degradation, this process has only been investigated indirectly in skeletal muscle during hypoxia via lipofuscin release, which reflects membrane damage (22).

In a study of the regulation of muscle mass by environmental hypoxia, many confounding factors have to be taken into account. Long-term hypoxia at extreme altitude is known to reduce appetite and energy intake (23) and to disturb the sleep cycle (24), thereby indirectly favoring a catabolic state. It is thus difficult to determine whether the reduction in muscle mass observed after long-term exposure to hypoxia is due to hypoxia per se or to the aforementioned con- founding factors. By simulating high altitude in a hypoxic facility, we were able to standardize the nutritional status of the subjects. To the best of our knowledge, D'Hulst et al. (25) from our laboratory are the only researchers to have systematically studied the effect of hypoxia on anabolic and catabolic signaling pathways in human skeletal muscle. Whereas protein degradation was only marginally enhanced, PKB and S6K1 phosphorylations were higher in skeletal muscles of subjects resting for $4 \mathrm{~h}$ in hypoxia, which contrasted with previously published reports $(11-13,17)$. However, autophagy was not assessed in this previous study, and how skeletal muscle protein metabolism is regulated by hypoxia after exercise in human remains unknown. Against this background, we investigated the effect of acute environmental hypoxia on markers of muscle protein synthesis and protein breakdown before and after a submaximal cycling session. Based on the majority of published data, we hypothesized that acute normobaric hypoxia would induce a negative net protein balance by repressing anabolic and activating proteolytic signaling pathways at rest and postexercise. In addition, the unique study sample of monozygotic (MZ) twins enabled us to estimate the genetic determination of protein and gene expression in response to hypoxia and/or exercise.

\section{MATERIALS AND METHODS}

\section{Subjects}

The data presented here are original except for arterial $\mathrm{O}_{2}$ saturation $\left(\% \mathrm{SpO}_{2}\right)$ and are part of a larger study in which 13 MZ twin pairs were enrolled. Of the 13 twins, 11 allowed muscle biopsy samples to be collected and are included in the present article $[n=22$; age, $24.4 \pm 0.8 \mathrm{yr}$; body weight, $75.9 \pm 1.7 \mathrm{~kg}$; maximal oxygen consumption $\left(V_{\mathrm{O}_{2 \max }}\right)$, $55.3 \pm 2.1 \mathrm{ml} \mathrm{O} / \mathrm{kg} / \mathrm{min}$ in normoxia and $33.5 \pm 1.3 \mathrm{ml}$ $\mathrm{O}_{2} / \mathrm{kg} / \mathrm{min}$ in hypoxia]. Data for $\% \mathrm{SpO}_{2}$ are presented elsewhere (unpublished results) but have been recalculated according to the number of twins used in the present report. Inclusion criteria were nonsmoking, no history of cardiovascular or respiratory disease, similar fitness levels within twins, and no residence at altitude $>1500 \mathrm{~m}$ during 6 mo before the study. The study was approved by the local ethics committee and was performed in accordance with the Declaration of Helsinki. Subjects gave written consent after medical examination and being informed of all experimental procedures. Monozygosity was confirmed via 8 polymorphic markers [chromosome (chr) 13, GATA30H01 and GATA85D03; chr 18, GATA2E06, GATA64H04, and GATA88A12; and chr 21, GATA163G03, GATA24H09, and GATA71H10]. Twins were instructed to maintain habitual diet and physical activity levels during the study and to omit exercise for $24 \mathrm{~h}$ before each experimental day.

\section{Study design}

Subjects participated in 2 experimental days in a normobaric hypoxic facility at $20^{\circ} \mathrm{C}$ and $50 \%$ relative humidity (Sporting Edge, Sherfield on Loddon, UK) with a 2-wk washout period in between. The first experimental trial was in normoxia conditions (NOR; $F_{\mathrm{i}} \mathrm{O}_{2}=20.9 \%$ ) and the second in hypoxia 
conditions (HYP; $F_{\mathrm{i}} \mathrm{O}_{2}=10.7 \%$ ). The NOR experiment was done first to exclude possible "memory" effects due to preceding hypoxic exposure. Breakfast (700 kcal from $84 \%$ carbohydrates, $9 \%$ fat, and $7 \%$ protein) and later meals and snacks (1880 kcal from $76 \%$ carbohydrates, $12 \%$ fat, and $12 \%$ protein) and drinks ( $500 \mathrm{ml}$ of water $/ 2 \mathrm{~h}$ ) on the experimental days were standardized. On each day, twins reported to the hypoxic facility at 8:00 AM and were installed in a separate compartment to keep them ignorant about their brothers. They first rested for $5 \mathrm{~h}$ in a chair in either normoxia (NOR group) or while $F_{\mathrm{i}} \mathrm{O}_{2}$ was gradually decreased to $10.7 \%$ (HYP group), and they then stayed for $3 \mathrm{~h}$ in the target $F_{\mathrm{i}} \mathrm{O}_{2}$ for the experimental protocol. A blood sample was taken preexercise (pre-ex) from an antecubital vein, and a biopsy sample, with the needle pointing proximally, was taken from the left musculus vastus lateralis under local anesthesia $(1 \mathrm{ml}$ of lidocaine) through a 5-mm incision in the skin. Subjects then performed a 20-min submaximal constant-load $(1.2 \mathrm{~W} / \mathrm{kg})$ exercise bout on a cycle ergometer (Cyclus II; Avantronic, Leipzig, Germany). The intensity of the exercise corresponded to $50.7 \pm 2.3 \%$ of $V_{\mathrm{O}_{2 \max }}$ in normoxia vs. $81.4 \pm$ $3.2 \%$ of $\mathrm{Vo}_{2 \max }$ in hypoxia. The load and the duration of the exercise were chosen after preliminary experiments had shown that $1.2 \mathrm{~W} / \mathrm{kg}$ for $20 \mathrm{~min}$ in similar subjects corresponded to near-maximal exercise tolerance at $F_{\mathrm{i}} \mathrm{O}_{2}$ of $10.7 \%$. A constant-load protocol was chosen to simulate an ascent to a summit during which climbers have to be roped together and move at the same pace. The same absolute intensity, instead of the same relative intensity, between normoxia and hypoxia was chosen because we were interested in knowing whether the response to a given absolute exercise intensity would be different in hypoxia than in normoxia. Immediately postexercise (post-ex), another blood sample and muscle biopsy sample (through the same incision as the pre-ex biopsy sample, but with the needle pointing distally) were taken. Venous blood samples were immediately centrifuged, and plasma was separated to be stored at $-20^{\circ} \mathrm{C}$ for later analysis of insulin. Muscle samples were quickly frozen in liquid nitrogen and stored at $-80^{\circ} \mathrm{C}$ until further analysis.

During each experimental session, $\% \mathrm{SpO}_{2}$ was measured continuously by a pulse oximeter (Nellcor N-600x; Covidien, St. Louis, MO, USA) with a sensor placed $\sim 2 \mathrm{~cm}$ above the right eyebrow. Local tissue oxygenation status of the right musculus vastus lateralis was continuously measured $(1 \mathrm{~Hz})$ by near-infrared spectroscopy (NIRO-200; Hamamatsu Photonics, Hamamatsu, Japan) via the tissue oxygenation index (TOI), which is a valid parameter to assess the fraction of $\mathrm{O}_{2}$-saturated tissue hemoglobin and myoglobin content (26). The probe was attached on the belly, in parallel with the long axis of the muscle.

\section{Plasma insulin}

The plasma insulin concentration was determined by ELISA using the ultrasensitive insulin kit from Mercodia (Uppsala, Sweden). In brief, plasma samples $(25 \mu \mathrm{l})$ were added onto a mouse monoclonal anti-insulin-coated plate with enzyme conjugate solution $(100 \mu \mathrm{l})$ and incubated for $1 \mathrm{~h}$ at room temperature. After 5 washes, tetramethylbenzidine (TMB) substrate $(200 \mu \mathrm{l})$ was added. After 5 min of incubation with TMB, $50 \mu \mathrm{l}$ of a stop solution containing $0.5 \mathrm{M} \mathrm{H}_{2} \mathrm{SO}_{4}$ was added, and absorbance was read at $450 \mathrm{~nm}$.

\section{Western blot}

Details of the immunoblotting procedures were described previously (27). In brief, frozen muscle tissue ( $\sim 20 \mathrm{mg})$ was homogenized 3 times for $5 \mathrm{~s}$ each with a Polytron mixer
(Polytron Technologies, Taoyuan City, Taiwan) in ice-cold buffer [1:10, w/v; $50 \mathrm{mM}$ Tris-HCl, $\mathrm{pH} 7.0 ; 270 \mathrm{mM}$ sucrose; $5 \mathrm{mM}$ EGTA; $1 \mathrm{mM}$ EDTA; $1 \mathrm{mM}$ sodium orthovanadate; 50 $\mathrm{mM}$ glycerophosphate; $5 \mathrm{mM}$ sodium pyrophosphate; $50 \mathrm{mM}$ sodium fluoride; $1 \mathrm{mM}$ dithiothreitol; $0.1 \%$ Triton $\mathrm{X}-100$; and a complete protease inhibitor tablet (Roche Applied Science, Vilvoorde, Belgium) ]. Homogenates were then centrifuged at $10,000 \mathrm{~g}$ for $10 \mathrm{~min}$ at $4^{\circ} \mathrm{C}$. The supernatant was collected and immediately stored at $-80^{\circ} \mathrm{C}$. The protein concentration was measured using a DC protein assay kit (Bio-Rad Laboratories, Nazareth, Belgium). Proteins $(30-80 \mu \mathrm{g})$ were separated by SDS-PAGE $(8-12 \%$ gels) and transferred to polyvinylidene difluoride membranes. Subsequently, membranes were blocked with $5 \%$ nonfat milk for $1 \mathrm{~h}$ and then incubated overnight $\left(4^{\circ} \mathrm{C}\right)$ with the following antibodies (1:1000): phospho-Akt/ PKB Ser ${ }^{473}$, Akt/PKB pan, ATG12, phospho-5'-AMP-activated protein kinase (AMPK) Thr ${ }^{172}$, total AMPK, total eukaryotic elongation factor 2 (eEF2), phospho-S6K1 Thr ${ }^{389}$, total S6K1, phospho-4E-BP1 $\mathrm{Thr}^{37 / 46}$, total 4E-BP1, p-FoxO1 $\mathrm{Thr}^{24}$ / FoxO3a $\mathrm{Thr}^{32}$, total FoxO3a, and LC3 (Cell Signaling, Leiden, The Netherlands); REDD1 (Bio-Connect, Huissen, The Netherlands); p62/SQSTM1 (Progen; Biotechnik, Heidelberg, Germany); MAFbx (Emelca Bioscience, Breda, The Netherlands); and MuRF-1 (Santa Cruz Biotechnology, Heidelberg, Germany). Horseradish peroxidase-conjugated anti-rabbit (1:5000) and anti-guinea pig (1:5000) secondary antibodies (Sigma-Aldrich, Bornem, Belgium) were used for chemiluminescent detection of proteins. Membranes were scanned and quantified with GeneSnap and Gene Tools software (Syngene, Cambridge, UK), respectively. Then, membranes were stripped and reprobed with the antibody for the total form of the respective protein to ascertain the relative amount of the phosphorylated protein compared with the total form throughout the whole experiment. The results are presented as the ratio protein of interest/eEF2 or as the ratio phosphorylated/total forms of the proteins when the phosphorylation status of the protein was measured. All values from the respective condition were reported to the mean value of the first sample (pre-ex) in NOR.

\section{RNA extraction and reverse transcription}

The method used for reverse transcription is described in detail elsewhere $(28,29)$. In brief, total RNA was extracted using TRIzol (Invitrogen, Vilvoorde, Belgium) from $20-25 \mathrm{mg}$ of frozen muscle tissue. Total RNA was extracted in 19 subjects because of the lack of material in 3 individuals. RNA quality and quantity were assessed by spectrophotometry with a NanoDrop (Thermo Scientific, Erembodegem, Belgium). Then $1 \mu \mathrm{g}$ of RNA was reverse-transcribed using a High-Capacity cDNA Reverse Transcription kit (Applied Biosystems, Gent, Belgium) according to the manufacturer's instructions.

\section{Real-time quantitative PCR analysis}

A SYBR Green-based master mix (Applied Biosystems) was used for real-time PCR analyses using the ABI PRISM 7300 system (Applied Biosystems). Real-time PCR primers were designed for human MuRF-1, MAFbx, Bcl-2/adenovirus E1B 19-kDa proteininteracting protein 3 (Bnip3), proliferating cell nuclear antigen (PCNA), and myostatin (MSTN; Table 1). Thermal cycling conditions consisted of 40 3-step cycles including denaturation for $30 \mathrm{~s}$ at $95^{\circ} \mathrm{C}$, annealing for $30 \mathrm{~s}$ at $58^{\circ} \mathrm{C}$, and extension for $30 \mathrm{~s}$ at $72^{\circ} \mathrm{C}$. All reactions were performed in triplicate. To compensate for variations in input RNA amounts and efficiency of reverse transcription, glyceraldehyde-3-phosphate dehydrogenase (GAPDH) and ribosomal protein L4 (RPL4) mRNA were quantified, and results were normalized to these values. These 


\begin{tabular}{lll}
\hline \hline \multirow{2}{*}{ Primer } & \multicolumn{2}{c}{ Sequences } \\
\cline { 2 - 3 } MuRF-1 & \multicolumn{1}{c}{ Forward } & \multicolumn{1}{c}{ Reverse } \\
MAFbx & CCCAAGGAAAGAGCAGTATGGAGA & CGCCACCAGCATGGAGATACA \\
Bnip3 & CTGAAACAGATACCCATAGCATT & CCGACTTGACCAATCCCA \\
PCNA & ATCCTCAAGAAGGTGTTGGAGGCA & ACGAGTCCATGCTCTGCAGGTTTA \\
MSTN & CTACAACGGAACAATCATTACCA & GTTTCAGAGATCGGATTCCAGTAT \\
GAPDH & CATGTTCGTCATGGGTGTGACCA & AGTGATGGCATGGACTGTGGTCAT \\
RPL4 & ATACGCCATCTGTTCTGCCCT & GCTTCCTTGGTCTTCTTGTAGCCT \\
\hline
\end{tabular}

genes were chosen out of 3 normalization genes using the GeNorm applet according to the guidelines and theoretical framework described elsewhere (30). All values from the respective condition were reported to the mean value of the first sample (pre-ex) in NOR.

\section{Statistical analysis}

A 2-way repeated-measures analysis of variance (ANOVA) was used to assess the statistical significance of differences between mean values over time and between conditions (Systat Software, San Jose, CA, USA). When appropriate, a Bonferroni $t$ test was used as a post hoc test. In addition, the correlated observations at the level of the twins, together with the individual repeated measures of the oxygen level conditions and exercise response (time) were also analyzed using a multilevel mixed-model approach (random effects for time level nested in condition level, nested in twin level; SAS 9.3; SAS Institute, Cary, NC, USA). Because the multilevel mixed-model approach gave the same significant results as the ANOVA, it was chosen to present all data according to the results of the 2-way repeated-measures ANOVA analyses. When the latter analyses revealed a significant difference in protein or mRNA expression, the genetic influence was determined by 2-way repeated-measures ANOVA on one factor, with the twins nested in pairs, and by intraclass correlation coefficients (ICCs; ref. 31; SAS Enterprise Guide 4.3, SAS Institute). $F$ ratios thus obtained represent the ratio of between-pair over within-pair variability in the induced responses, whereas ICCs provide a quantitative estimate of the similarity within MZ twin pairs and an upper-limit estimate of the genetic component in these responses (genotype $\times$ hypoxia and genotype $\times$ exercise interaction). A probability level of $P<0.05$ was considered statistically significant. All data are means \pm SEM.

\section{RESULTS}

\section{Arterial and muscle tissue oxygenation status}

Compared with exposure to NOR, exposure to HYP caused a $22 \%$ decrease in $\% \mathrm{SpO}_{2}$ pre-ex $(P<0.05)$ and another $6 \%$ decrease post-ex $(P<0.05$; Table 2$)$. HYPinduced changes in $\% \mathrm{SpO}_{2}$ were accompanied by lower TOI both pre-ex $(-5 \%, P<0.05)$ and post-ex $(-9 \%$, $P<0.05)$. In NOR, exercise decreased muscle TOI $(-6 \%, P<0.05)$ without modifying $\% \mathrm{SpO}_{2}$.

\section{PKB/mTOR pathway}

No significant differences were found between NOR and HYP for PKB (Fig. 1A), S6K1 (Fig. 1B), and 4E-BP1
(Fig. 1C) phosphorylation and plasma insulin levels (Fig. $1 D$ ) whether at rest or post-ex. Post-ex, phosphorylation of PKB at Ser $^{473}$ decreased by $35 \%$ in NOR $(P<0.05)$ and $29 \%$ in HYP $(P<0.05$; Fig. $1 A)$. This exercise-induced dephosphorylation was also observed for PKB downstream targets, S6K1 at $\mathrm{Thr}^{389}$ (NOR: $-51 \%$, HYP: $-47 \%, P<0.05$; Fig. $1 B$ ) and $4 \mathrm{E}-\mathrm{BP} 1$ at $\mathrm{Thr}^{37 / 46}$ (NOR: $-15 \%$, HYP: $-19 \%, P<0.05$; Fig. $1 C$ ). Furthermore, exercise reduced plasma insulin in both NOR $(-46 \%, P<0.05)$ and HYP $(-34 \%, P<0.05$; Fig. $1 D)$. REDD1 and AMPK are known to inhibit the mTOR pathway and to be up-regulated in hypoxia (32). In HYP compared with NOR, phosphorylation of AMPK at $\mathrm{Thr}^{172}$ (Fig. 1E) and REDD1 protein expression (Fig. $1 F$ ) were increased both pre-ex and post-ex. In addition to those individual responses, the unique study sample of MZ twins gave the opportunity to estimate the genetic determination of protein and gene expressions in response to hypoxia and/or exercise (Table 3). In response to hypoxia, a large interindividual variability was found for $\triangle$ REDD1 protein expression pre-ex (0.7- to 29.8-fold) and post-ex (0.2- to 44.7-fold). However, these expressions were not randomly distributed and high similarities within twin pairs were found, indicating a familial and most likely a genetic influence. The response to hypoxia of each twin pair for the expression of REDD1 pre-ex and post-ex is presented in Fig. $1 H$, $I$, respectively. $\triangle$ REDD1 was highly similar within twin pairs pre-ex $(\mathrm{ICC}=0.87$, $P<0.05$; Fig. $1 H$ ), with 6.5 -fold higher variability between pairs than within pairs, and post-ex $(\mathrm{ICC}=0.93$, $P<0.05$; Fig. $1 I$ ), with 13.2 -fold higher variability between pairs than within pairs.

TABLE 2. Effect of hypoxia on arterial $\mathrm{O}_{2}$ saturation and muscle tissue oxygenation status pre-ex and post-ex

\begin{tabular}{lcc}
\hline \hline Parameter & NOR & HYP \\
\hline$\% \mathrm{SpO}_{2}$ & & \\
Pre-ex & $99.3 \pm 0.2$ & $79.3 \pm 0.9^{*}$ \\
Post-ex & $97.6 \pm 0.3$ & $70.6 \pm 0.7^{*}$, \\
TOI $(\%)$ & & \\
Pre-ex & $68.9 \pm 0.3$ & $65.7 \pm 0.3^{*}$ \\
Post-ex & $64.2 \pm 0.3^{\#}$ & $58.6 \pm 0.5^{*}, \#$ \\
\hline
\end{tabular}

Values are means \pm SEM $(n=22)$ for $\% \mathrm{SpO}_{2}$ and muscle TOI pre-ex and post-ex in NOR and HYP groups. $* P<0.05$ vs. NOR; ${ }^{\#} P<0.05$ ws. pre-ex. 
A

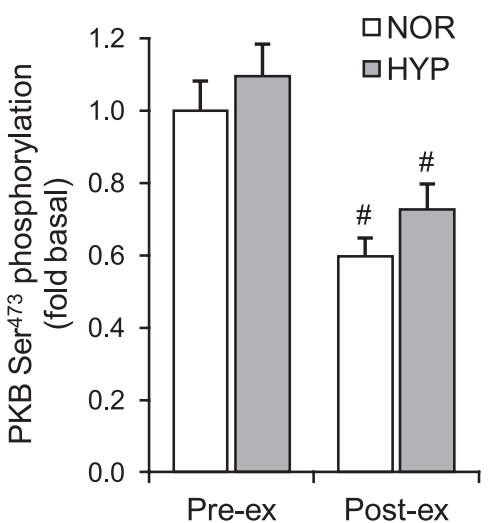

D

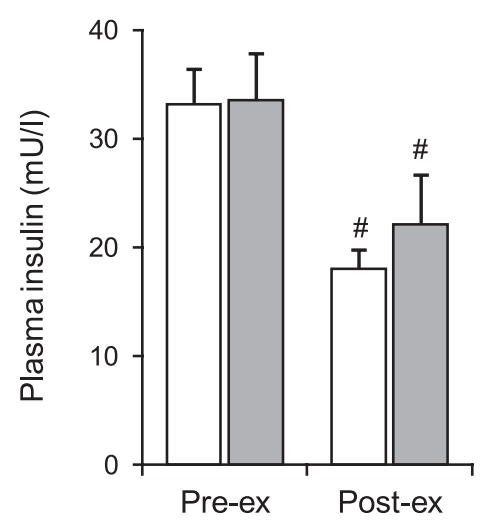

G

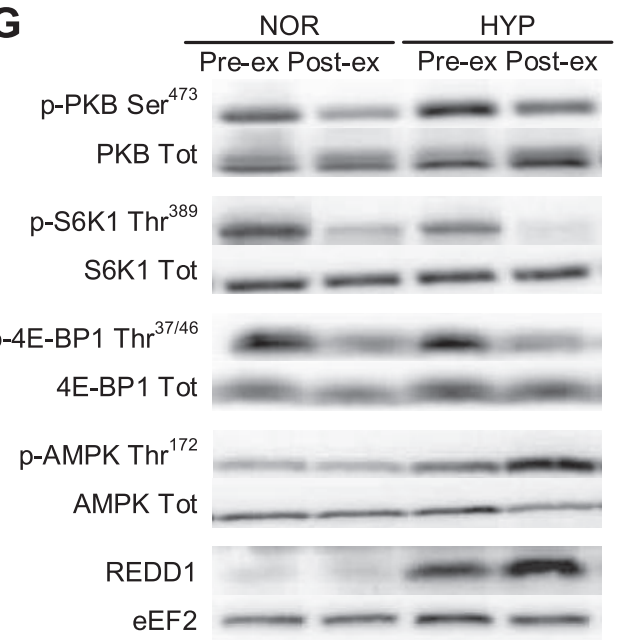

B

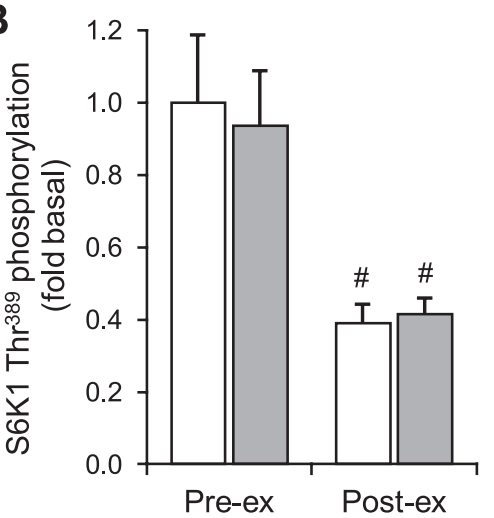

E

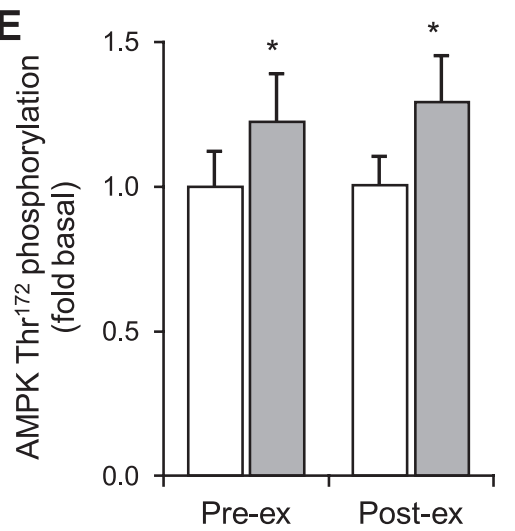

H

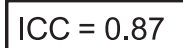

F-ratio $=6.59$

$(P<0.05)$

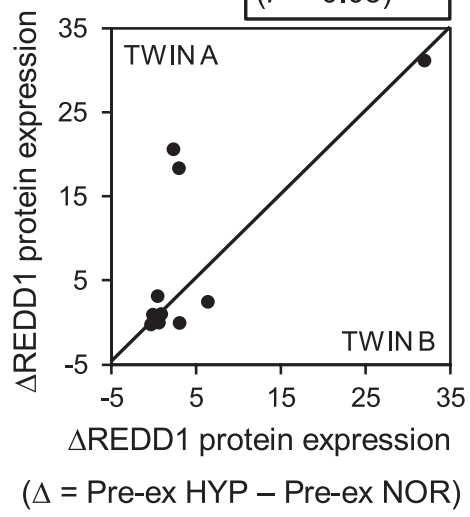

C

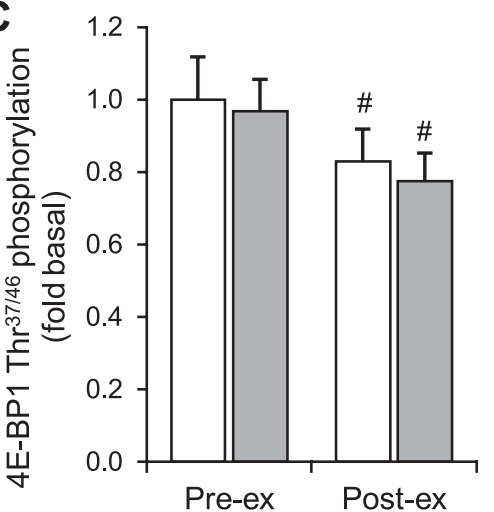

$\mathbf{F}$

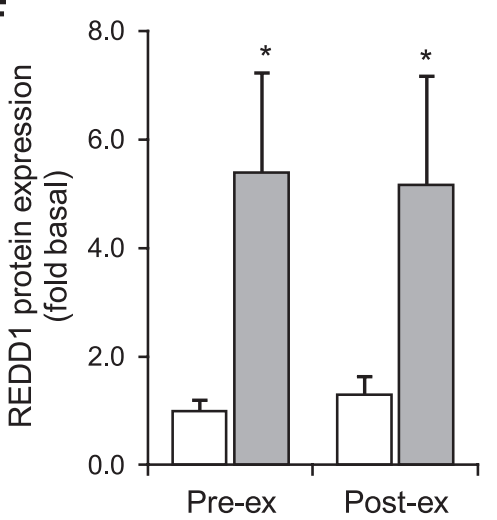

I

ICC $=0.93$

F-ratio $=13.23$

$(P<0.05)$

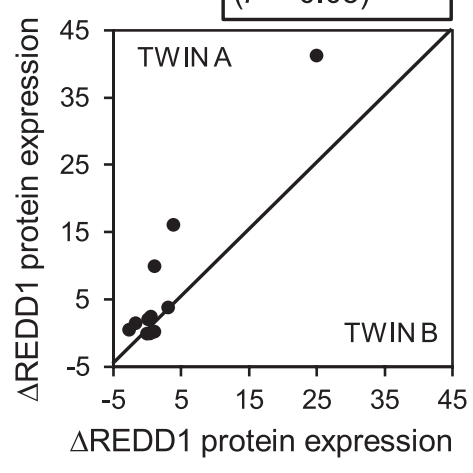

( $\Delta=$ Post-ex HYP - Post-ex NOR)

Figure 1. Effect of environmental hypoxia and exercise on the PKB/mTOR pathway. $A-F)$ PKB $(A)$, S6K1 $(B)$, and 4E-BP1 $(C)$ phosphorylation, plasma insulin levels $(D)$, AMPK phosphorylation $(E)$, and REDD1 protein expression $(F)$ pre-ex and post-ex in NOR and HYP groups. G) Representative blots. Data are means \pm SEM $(n=22) . * P<0.05$ vs. NOR; ${ }^{*} P<0.05$ vs. pre-ex. $H$, I) HYP-induced changes $(\Delta)$ in REDD1 protein expression pre-ex $(H)$ and post-ex $(I)$ are presented for 11 pairs of MZ twins. Each point represents one pair of twins (twin A and twin B). ICCs and corresponding $F$ ratios (between/within pairs variance) are illustrated in the figure.

\section{Autophagy-related markers}

The nonlipidated form of LC3 (LC3-I) was not modified at rest in HYP compared with NOR but was lowered post-ex in HYP $(-17 \%, P<0.05$; Fig. 2A). Exercise had no effect on LC3-I in NOR (Fig. 2A). The lipidated form of LC3 (LC3-II) is used as a valuable marker of the presence of autophagosomes in the cell (33). At rest, LC3-II and the LC3-II/I ratio were increased in HYP compared with NOR by $45 \%(P<0.05)$ and $29 \%(P<0.05)$, respectively (Fig. $2 B, C$ ). However, this increase in HYP at rest was entirely reversed post-ex because LC3-II and LC3-II/I were decreased by $32 \%(P<0.05)$ and $44 \%$ $(P<0.05)$, respectively, reaching values similar to those in NOR. The ATG5-conjugated form of ATG12 (cATG12) was not affected by any condition (Fig. 2D). p62/SQSTM1 is another autophagy marker that is 


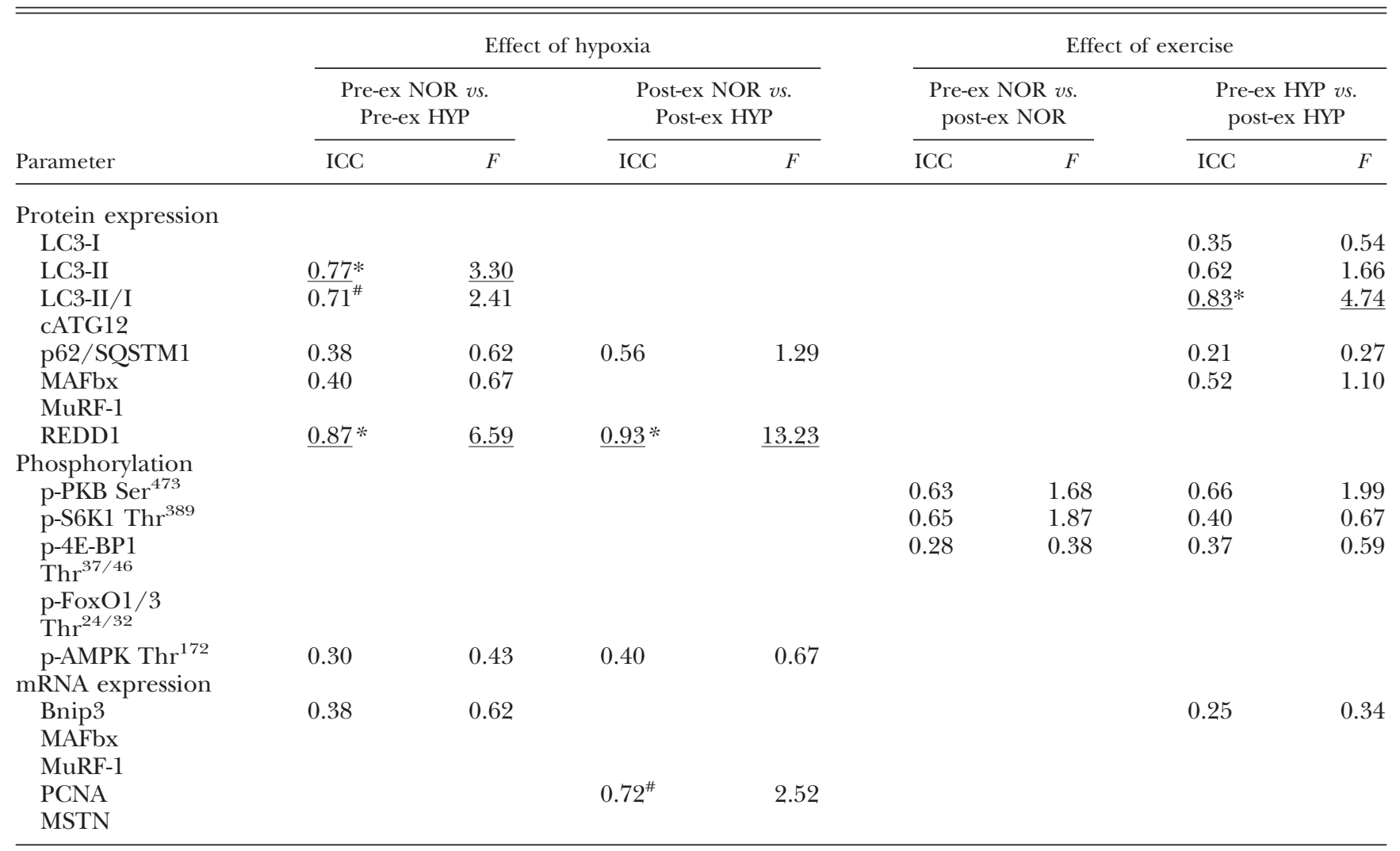

ICCs and corresponding $F$ ratios (between/within pairs variance) represent similarity within twin pairs for the response to hypoxia pre-ex and post-ex and the response to exercise in NOR and HYP groups. Underscored results are presented in Figs. 1 and 2, where each twin pair response is illustrated. A full report containing all ICCs can be found in Supplemental Table S1. $n=11$ twins for protein expression and phosphorylation, and $n=8$ twins for mRNA expression. ${ }^{*} P<0.05 ;{ }^{\#} P<0.10$.

involved in linking polyubiquitinated protein aggregates to the autophagy machinery and is degraded by the lysosome together with the aggregates. Therefore, p62/SQSTM1 can be used as a marker of the autophagic flux (34). In HYP compared with NOR, p62/ SQSTM1 was decreased pre-ex and post-ex by 25 and $15 \%$, respectively (Fig. 2E). Furthermore, compared with pre-ex levels, p62/SQSTM1 was decreased post-ex in HYP $(-15 \%, P<0.05)$ but not in NOR. mRNA expression of Bnip3, a mitophagy-related gene (35), was increased by $34 \%$ at rest in HYP compared with that in NOR $(P<0.05)$ but returned to a level similar to that in NOR post-ex $(P<0.05$; Fig. $2 F)$. As for REDD1, a high similarity between twins was found in the response to HYP at rest for LC3-II protein expression (Fig. $2 H$ ) and in the response to exercise in HYP for the ratio LC3-II/I (Fig. 2I). DLC3-II was highly similar within twin pairs pre-ex $(\mathrm{ICC}=0.77, P<0.05$; Fig. $2 H)$, with 3.3-fold higher variability between pairs than within pairs. High MZ twin pair resemblance was also found for $\Delta \mathrm{LC} 3-\mathrm{II} / \mathrm{I}$ in the response to exercise in HYP $(\mathrm{ICC}=0.83, F$ ratio $=4.74, P<0.05$; Fig. $2 I)$.

\section{Ubiquitin-proteasome-related markers}

MAFbx mRNA expression was increased by $18 \%$ $(P<0.05$; Fig. $3 A)$ at rest in HYP compared with NOR and returned to values similar to those in NOR post-ex
$(P<0.05)$. MuRF-1 mRNA expression did not change at rest in HYP or post-ex (Fig. $3 B$ ). At the protein level, MAFbx (Fig. 3C) and MuRF-1 (Fig. 3D) were not modified by any condition. The transcription of MAFbx and MuRF-1 is under the control of a family of transcription factors called FoxO (36), among others. However, phosphorylation of FoxO1/3a at $\mathrm{Thr}^{24 / 32}$ was not different in any condition (Fig. $3 E$ ).

\section{Muscle growth markers}

PCNA is a marker of DNA synthesis and satellite cell proliferation (37). PCNA mRNA expression was not modified at rest, whereas it was significantly increased post-ex in HYP compared with that in NOR $(+32 \%, P<0.05$; Fig. $4 A)$. A trend for high MZ twin pair similarity was found in the response to exercise in HYP $(\mathrm{ICC}=0.72, F$ ratio $=2.52, P<0.10$; Table 3 ). Exercise had no effect on PGNA mRNA expression in NOR. MSTN, an inhibitor of muscle differentiation and growth, was not affected by any condition.

\section{DISCUSSION}

Hypoxia-induced muscle wasting is a phenomenon often described as a consequence of high altitude 

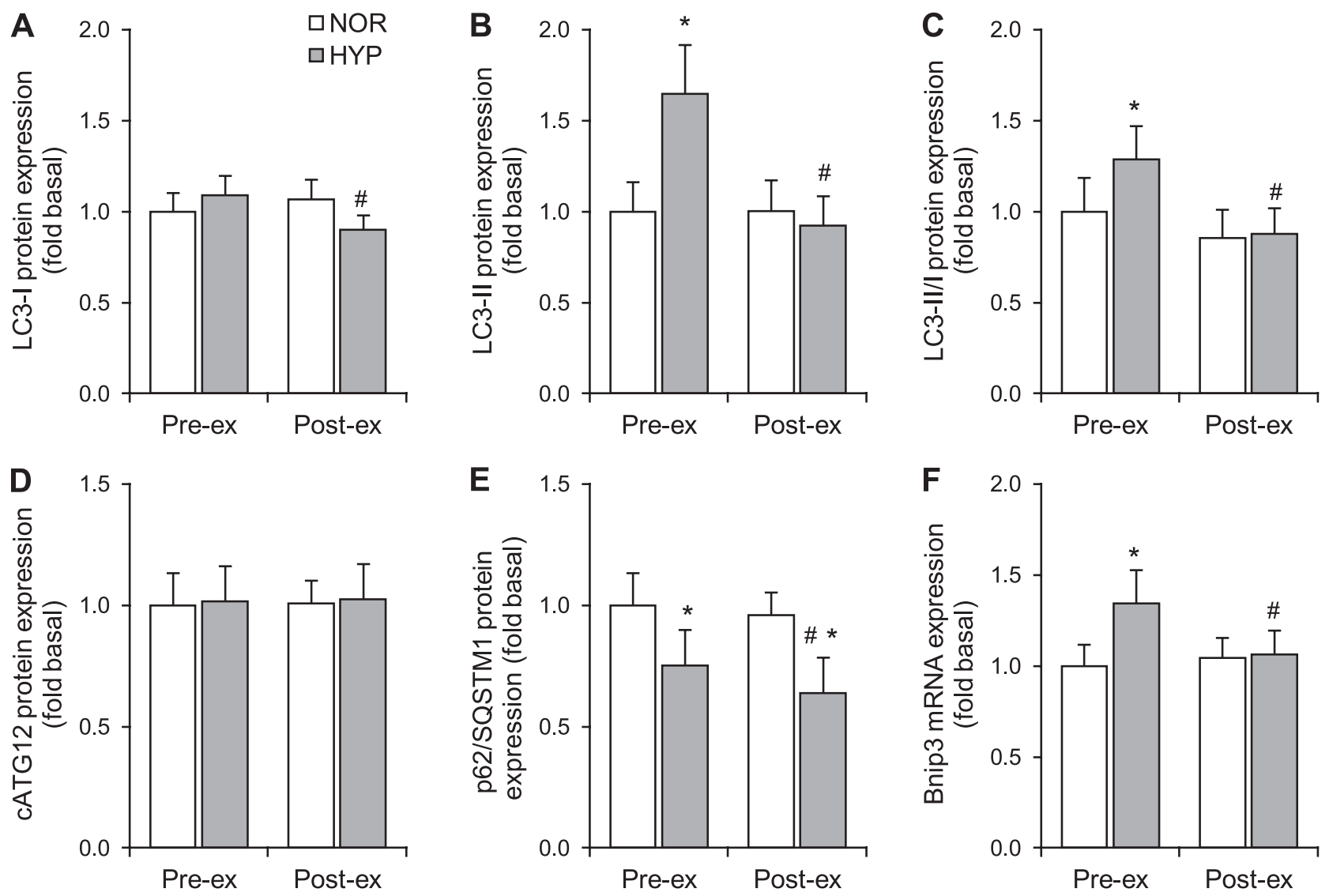

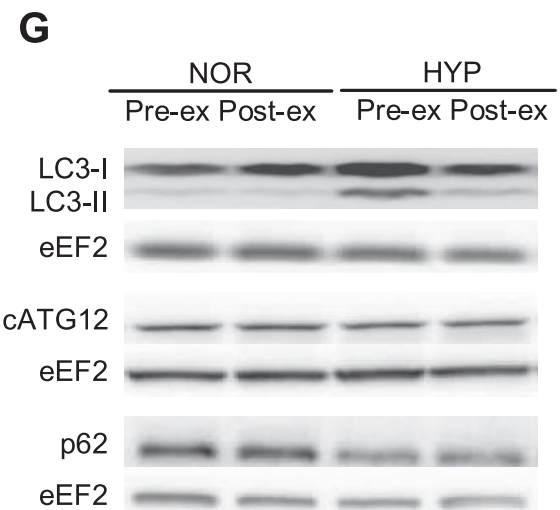

Figure 2. Effect of environmental hypoxia and exercise on autophagy- and mitophagy-related markers. $A-F)$ LC3-I $(A)$, LC3-II $(B)$, LC3-II/I $(C)$, cATG12 $(D)$, and p62/SQSTM1 $(E)$ protein expressions $(n=22)$ and Bnip3 mRNA expression $(F ; n=19)$ pre-ex and post-ex in NOR and HYP groups. $G)$ Representative blots. Data are means \pm sem. ${ }^{*} P<0.05$ vs. NOR; ${ }^{\#} P<0.05$ vs. pre-ex. $\left.H, I\right)$ HYP-induced changes $(\Delta)$ in LC3-II protein expression at rest $(H)$ and exercise-induced changes $(\Delta)$ in LC3-II/I ratio $(I)$ in HYP are presented for 11 pairs of MZ twins. Each point represents one pair of twins (twin A and twin B). ICCs and corresponding $F$ ratios (between/within pairs variance) are illustrated in the figure.
$(38,39)$ and several pathological conditions $(40,41)$; however, the molecular mechanisms underlying the loss of human skeletal mass are poorly understood. Therefore, we designed a well-controlled study in our normobaric hypoxic chamber to investigate anabolic and catabolic signaling pathways in response to hypoxia. We show for the first time that exposure to environmental hypoxia increased LC3 lipidation and decreased p62/SQSTM1 protein expression in skeletal muscle, which together indicate a higher rate of autophagic initiation and degradation and thus higher autophagic flux (42). Responses in LC3 lipidation showed large individual differences with high MZ twin similarity, which point to the role of underlying genetic variants to at least partially explain these differences. 

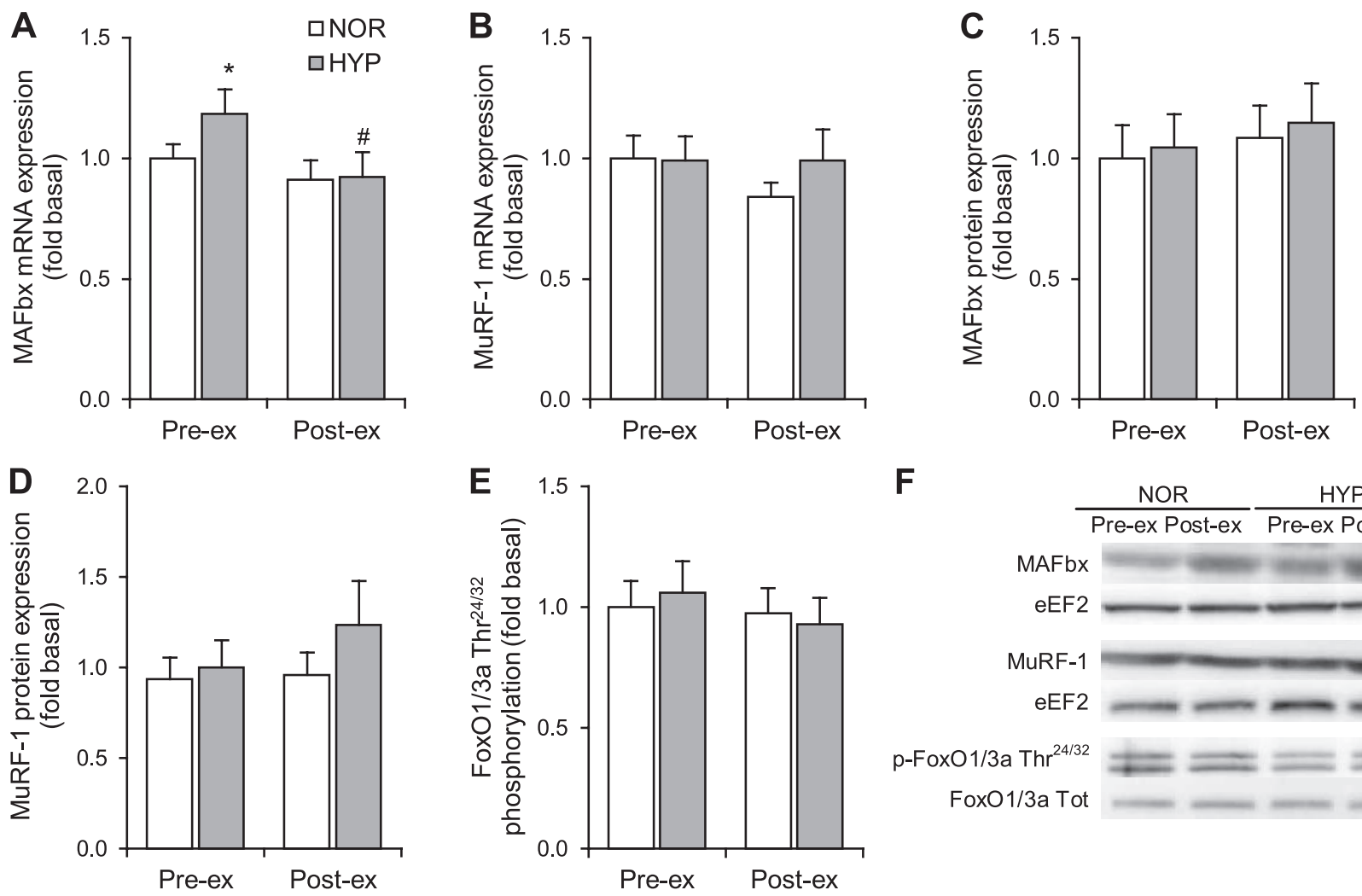

$\mathbf{F}$
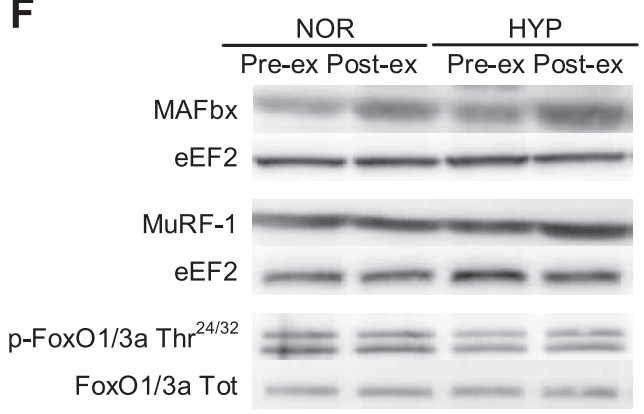

Figure 3. Effect of environmental hypoxia and exercise on ubiquitin-proteasome-related markers. $A-E)$ MAFbx (A) and MuRF-1 $(B)$ mRNA expressions $(n=19)$, MAFbx $(C)$ and MuRF-1 $(D)$ protein expressions, and FoxO1/3a phosphorylation $(E$; $n=22)$ pre-ex and post-ex in NOR and HYP groups. $F)$ Representative blots. Data are means \pm sem. ${ }^{*} P<0.05$ vs. NOR; ${ }^{\#} P<0.05$ vs. pre-ex.

\section{Activation of autophagy by acute environmental hypoxia}

Until now, research has mainly focused on muscle protein synthesis, and less is known about muscle protein degradation in hypoxia, certainly in humans. Two major proteolytic pathways control protein degradation in skeletal muscle: the ubiquitin-proteasome and the autophagy-lysosomal pathways (19). To the best of our knowledge only one study evaluated the effect of hypoxia on the autophagy-lysosomal pathway (22). In that study, the volume density of lipofuscin was used as a marker for mitochondria and lysosome membrane damage. More lipofuscin was found in skeletal muscle of climbers staying for $8 \mathrm{wk}$ at $>5000 \mathrm{~m}$. Whether other markers of the autophagy-lysosomal pathway are modified under hypoxic conditions is not known, nor is the effect of acute hypoxia.

The present study shows for the first time an increase in protein markers of the autophagy-lysosomal pathway in response to short-term environmental HYP in human skeletal muscle. Autophagosome formation is under the control of ATG proteins, including the ATG12ATG5 complex and ATG8 or LC3. In the present study, no alteration was found in cATG12; however, the lipidated form of LC3, LC3-II, increased in hypoxia. The conversion of cytosolic microtubule-associated pro-
Figure 4. Effect of environmental hypoxia and exercise on muscle growth-related genes. $A, B$ ) PCNA $(A)$ and MSTN $(B)$ mRNA expressions pre-ex and post-ex in NOR and HYP groups. Data are means $\pm \operatorname{SEM}(n=19) .{ }^{*} P<0.05$ vs. NOR.
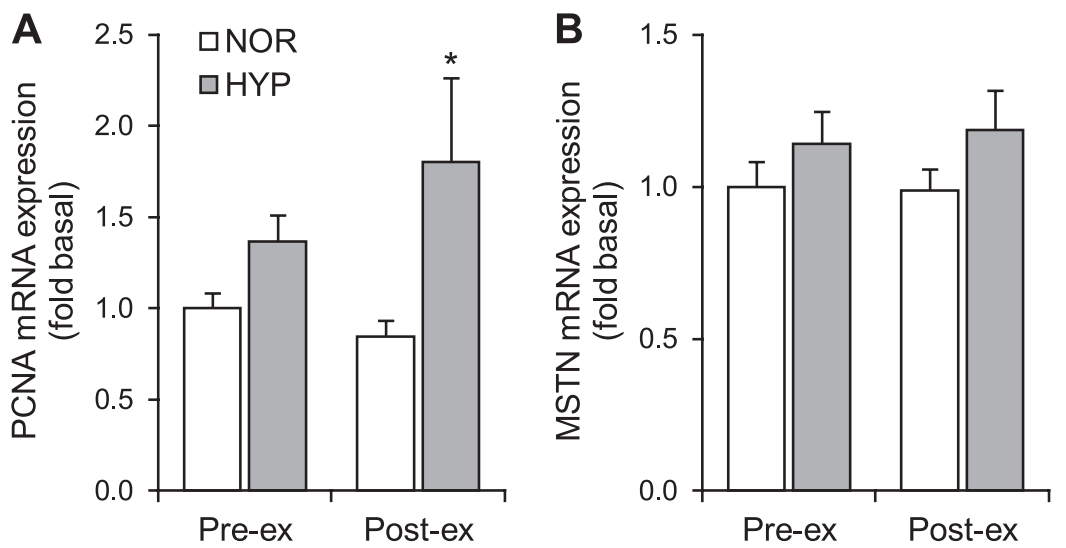
tein I (LC3-I) to the autophagosomal membrane-associated form (LC3-II), is a marker of autophagic activity, whereas LC3-II alone is used as a valuable marker of the presence of autophagosomes in the cell (33). We found a large increase in LC3-II/I and LC3-II in response to hypoxia, suggesting an increase in autophagic activity and the presence of autophagosomes. However, this conclusion has to be drawn with caution because an increase in LC3 lipidation reflects increased autophagosome formation due to either an increase in autophagic activity or a reduced turnover of autophagosomes (42). Indeed, during autophagy, the autophagosomes fuse with lysosomes to form autolysosomes, and the autophagosomal content is degraded by lysosomal hydrolases. At the same time, LC3 in the autolysosomal lumen is degraded. Therefore, an increase in LC3 may result from a reduced turnover of autophagosomes rather than from an increased autophagic activity. To get a better picture of the autophagic flux, p62/ SQSTM1 has to be determined together with LC3 expression. The p62/SQSTM1 protein serves as a link between LC3 and ubiquitinated substrates to deliver them selectively into the autophagosome (21). p62/ SQSTM1 is known to be degraded together with the autophagosome content and can thus be used as a marker of autophagic flux (34). In hypoxia, LC3-II and LC3-II/I were increased concomitantly with decreased p62/SQSTM1, indicating that the whole autophagic flux was increased. Following exercise in hypoxia, a decrease in LC3-I, LC3-II, and LC3-II/I as well as in p62/SQSTM1 protein levels was found compared with those under resting conditions in hypoxia, suggesting that the autophagosomes formed before exercise were degraded as a result of the endurance exercise (43). Together with the increase in Bnip3 mRNA, an important regulatory gene in autophagy and mitophagy (35, 44), our results suggest that autophagic activity in human skeletal muscle is enhanced in hypoxia, and this activity seems to be reduced by exercise, returning to a level similar to that observed in normoxia.

Two studies in rat skeletal muscle indicated that the ubiquitin-proteasome pathway may be responsible for enhanced protein degradation in skeletal muscle under acute and chronic hypoxia $(14,45)$. Furthermore, Chaillou et al. (15) have shown that hypoxia transiently impaired the overload-induced muscle hypertrophy, partially due to up-regulation of MAFbx and MuRF-1 mRNA expression in rat skeletal muscle. In human skeletal muscle, MuRF-1 mRNA expression increased, whereas MAFbx decreased during acute exposure to environmental hypoxia (25). A different regulation of those 2 E3 ligases was found in the present study because, during hypoxia, MAFbx mRNA increased at rest and returned to levels similar to those in normoxia after exercise, whereas MuRF-1 remained unchanged. However, those modifications were not found at the protein level, suggesting that in acute hypoxia, the ubiquitin-proteasome pathway plays no major role in human skeletal muscle.

In skeletal muscle, FoxO1 and FoxO3a have been identified as critical transcription factors controlling proteolysis. FoxOs stimulate protein degradation by transcriptional activation of key genes from both the ubiquitin-proteasome pathway and autophagy-lysosomal pathway $(44,46)$. The activity of FoxOs is primarily regulated by their phosphorylation state (47). In a catabolic state, phosphorylated FoxOs translocate from the cytosol to the nucleus and bind to target genes. We found no change in phosphorylation state for FoxOs, suggesting that the ubiquitinproteasome pathway and the autophagy-lysosomal pathway are controlled through an alternative pathway independent from FoxOs.

\section{No alteration of the mTORC1 pathway by acute environmental hypoxia}

The main findings of the present study suggest that hypoxia modulates protein metabolism primarily by altering markers of protein breakdown, whereas anabolic signaling is not preferentially altered in hypoxia. These results are in contrast to earlier findings in our laboratory (25), which show that hypoxia activates the mTORC1 pathway in a way that is theoretically favorable for muscle protein accretion. However, the purpose of that previous study was to investigate the response to a meal while the subjects were sitting in a hypoxic environment for $4 \mathrm{~h}$. Compared with this previous study in which the unique meal was taken in normoxia, here food intake was spread over the 8-h experimental trial. The mTORC1 pathway was upregulated in hypoxia, probably due to higher plasma insulin levels (25), whereas in the present study, insulin levels were not altered by hypoxia. No clear reason to explain this difference in insulin concentrations was found, but the nutritional pattern was different in both studies, which could have elicited different insulin regulation. In addition, it is possible that the gradual decrease of $F_{\mathrm{i}} \mathrm{O}_{2}$ in the present study (from 20.9 to $10.7 \%$ inspired $\mathrm{O}_{2}$ over $5 \mathrm{~h}$ ), compared with the more stressful direct exposure to the targeted $F_{\mathrm{i}} \mathrm{O}_{2}$ in D'Hulst et al. $\left(25 ; 11 \%\right.$ inspired $\left.\mathrm{O}_{2}\right)$, could have induced a smaller catecholamine response or a response that did not elicit any modification in insulin production (48). However, a lack of information about plasma catecholamine levels in both studies only allows speculation. The differences in the protocols can probably explain some of the differences measured in both studies. With the present protocol, we tried to reflect better what happens during a real ascent, i.e., meals taken in progressively increasing hypoxia.

Several in vitro and animal models have shown decreased muscle protein synthesis in hypoxia $(11,49-$ $51)$. One study reported decreased mTOR protein content after 7-9 d of exposure to $4559 \mathrm{~m}$, but no change in eukaryotic translation initiation factor $2 \alpha$ $($ eIF2 $\alpha$ ) was observed (52). Furthermore, acute hypobaric hypoxia has been shown to slow protein synthesis in the forearm muscle compartment (estimated by leucine uptake; ref. 53) and a blunted exercise-induced 
increase in muscle protein synthesis after $3.5 \mathrm{~h}$ in normobaric hypoxia $\left(12 \%\right.$ inspired $\mathrm{O}_{2}$ ) has been found (54). Conversely, in another study, the myofibrillar protein synthesis rate was doubled after 7-9 $\mathrm{d}$ of

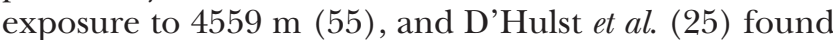
that markers of muscle protein synthesis (PKB and S6K1) were activated after $4 \mathrm{~h}$ in normobaric hypoxia (11\% inspired $\mathrm{O}_{2}$ ). However, in the present study, hypoxia did not alter the phosphorylation state of markers of protein synthesis, i.e., PKB, S6K1, and 4E-BP1. Immediately after exercise, a decrease in the phosphorylation state of those proteins was found in both normoxia and hypoxia, with no differences between conditions. Those results indicate that exercise was a more potent signal for regulating the PKB/ mTOR pathway than hypoxia in our conditions, probably by regulating plasma insulin concentration, because the decrease in the phosphorylation state of PKB, $\mathrm{S} 6 \mathrm{~K} 1$, and 4E-BP1 paralleled the decrease in insulin concentration after exercise.

\section{REDD1 and AMPK do not inhibit the mTORC1 pathway}

The fact that the PKB/mTOR pathway was not altered by environmental hypoxia in our study is unexpected for 2 reasons. First, environmental hypoxia caused a drop in $\% \mathrm{SpO}_{2}$ by $22 \%$, which was accompanied by a $5 \%$ lower muscle TOI, indicating that hypoxia was present at the muscle level. Second, 2 markers known to be sensitive to hypoxia and to inhibit the mTORC1 pathway (32) were measured, i.e., REDD1 and AMPK. Our data show that despite a large increase in REDD1 protein expression and AMPK phosphorylation after acute exposure to environmental hypoxia, no inhibitory effect on the PKB/mTOR pathway was observed. Whereas the regulation of REDD 1 by exercise has only been poorly studied, it was quite surprising to observe that AMPK was not modified by our exercise protocol either in normoxia or in hypoxia. The relative exercise intensity in normoxia $\left(\sim 50 \% V_{\mathrm{O}_{2 \mathrm{max}}}\right)$ was low, which probably explains why AMPK phosphorylation was not altered. However, in hypoxia, the relative intensity corresponded to $\sim 80 \% \mathrm{Vo}_{2 \max }$ and should have elicited a higher phosphorylation state (56). It is therefore possible that our exercise protocol was not long enough to allow AMPK to be further phosphorylated compared with that under resting conditions in hypoxia because both intensity and duration determine the activation of AMPK (57). REDD1 and AMPK did not modify the phosphorylation of the PKB/mTOR pathway, nor was this the case for another potential inhibitor of this pathway, i.e., MSTN. MSTN, a member of the transforming growth factor- $\beta$ family, acts as a negative regulator of skeletal muscle mass, presumably through down-regulation of the $\mathrm{PKB} / \mathrm{mTOR}$ pathway (58), and it has also been shown to partly account for the hypoxia-induced wasting of muscle mass (59). However, neither hypoxia nor exercise modified the mRNA expression of myostatin in our study.

\section{MZ similarity in the molecular response to hypoxia and exercise}

Physiological adaptations to hypoxia vary widely among individuals (10). In the present study, we found large interindividual variability for the drop in $\% \mathrm{SpO}_{2}$ in hypoxia ranging from 15 to $32 \%$ at rest and from 20 to $35 \%$ after exercise. It has been suggested that genetic factors could be partially responsible for the variability in these adaptations (10). Up to now, a few genetic variants have been found to influence the physiological adaptations to hypoxia, such as variants in the angiotensin-converting enzyme, nitric oxide 3, peroxisome proliferator-activated receptor $\gamma$, or heat shock protein 70 genes (10). However, none of those genes is involved in the regulation of protein metabolism, and, at this time, it is not known whether genetic factors influence the regulation of muscle protein balance by hypoxia. Using an MZ twin design in the present study, we were able to partially answer this question, although the sample size was rather limited. Therefore, the threshold for significant ICCs was set at $>0.75$. Despite this limitation, large interindividual variability was found for some protein and mRNA expressions in response to hypoxia and/or exercise. However, those adaptations were not randomly distributed among subjects. A high MZ twin resemblance was found for the change in REDD1 and LC3-II protein expressions in response to hypoxia at rest and for the change in REDD1 in response to hypoxia after exercise, indicating that, if other common environmental factors are lacking, genetic factors are involved in those responses. REDD1 did not inhibit the mTORC1 pathway in the present study; therefore, its increase is of minor physiological significance, at least in the regulation of protein metabolism. On the contrary, the increase in LC3-II is an important initial step in the activation of autophagy together with the decrease in p62/SQSTM1, and we show here that the hypoxia-induced increase in LC3-II partially depends on genetic factors. To the best of our knowledge, this is the first study to demonstrate that the effect of hypoxia on molecular adaptations is familial and most likely genetically determined. We have to acknowledge that a limitation of the present study is that dizygotic twins were not included in the experimental design, which would have allowed discrimination between similarity-inducing factors of genetic and shared (common) environmental factors. The MZ twin exposure design has, however, been applied frequently by other groups to study genotype $\times$ environment interactions (31) and was earlier compared with a longitudinal design including $\mathrm{MZ}$ and dizygotic twins in a genotype $\times$ strength training interaction study (60), leading to similar interpretations. We therefore acknowledge that the reported twin resemblances reflect upper-limit heritabilities and the $F$ tests indicate an upper-limit estimation of genotype $\times$ HYP interaction because the contribution of shared/common environmental effects could not be tested. 


\section{Further perspectives}

Protein turnover is not only determined by protein synthesis and degradation but also by cell turnover, namely the addition of new myonuclei through satellite cell fusions and the loss of myonuclei through nuclear apoptosis (61). Satellite cells have been shown to become activated in vivo during muscle regeneration (62) and functional overload (63). Some in vitro models have also shown that hypoxia promotes satellite cell proliferation $(64,65)$. However, whether hypoxia activates satellite cells in vivo has not been investigated yet. Because PCNA has been shown to be a marker of satellite cell activation (37), we measured its mRNA level. For the first time, we show that in human skeletal muscle, PCNA mRNA expression was increased after exercise in hypoxia, with a substantial similarity within MZ pairs. Although we did not determine other markers because this was beyond the scope of the present study, further research to look at the regulation of satellite cell proliferation and/or activation by hypoxia alone or in combination with exercise might be promising. The moderate to high MZ similarities in LC3-II, REDD1, and PCNA responses merit further investigation into specific variants within these genes or other regulatory genes that might partially predict a higher sensitivity to muscle wasting in hypoxia-related conditions.

\section{CONGLUSIONS}

Our results indicate that environmental hypoxia modulates protein metabolism at rest and after moderate exercise by primarily altering markers of protein breakdown and more specifically markers of the autophagy-lysosomal system in human skeletal muscle. In addition, we show for the first time that some of those cellular adaptations to hypoxia alone or in combination with exercise depend on familial and most likely genetic factors, even though to a modest extent. Although protein breakdown was not directly assessed, our results suggest that the up-regulation of catabolic pathways could induce muscle atrophy during chronic hypoxia.

The authors thank Monique Ramaekers for skillful technical assistance during the experiments. The participation of the subjects is also gratefully acknowledged. Support for this study was provided by KU Leuven (research grant OT/09/ 033) and by the Fonds voor Wetenschappelijk OnderzoekVlaanderen (grants G.0706.09 and KAN.1.5.100.10N). The authors declare no conflicts of interest.

\section{REFERENCES}

1. Grocott, M. P., Martin, D. S., Levett, D. Z., McMorrow, R., Windsor, J., and Montgomery, H. E. (2009) Arterial blood gases and oxygen content in climbers on Mount Everest. N. Engl. J. Med. 360, 140-149

2. Baldi, S., Aquilani, R., Pinna, G. D., Poggi, P., De Martini, A., and Bruschi, C. (2010) Fat-free mass change after nutritional rehabilitation in weight losing COPD: role of insulin, C-reactive protein and tissue hypoxia. Int. J. Chron. Obstruct. Pulmon. Dis. 5, 29-39

3. Garvey, J. F., Taylor, C. T., and McNicholas, W. T. (2009) Cardiovascular disease in obstructive sleep apnoea syndrome: the role of intermittent hypoxia and inflammation. Eur. Respir. J. 33, 1195-1205

4. Grocott, M., Montgomery, H., and Vercueil, A. (2007) Highaltitude physiology and pathophysiology: implications and relevance for intensive care medicine. Crit. Care 11, 203

5. Beall, C. M. (2007) Two routes to functional adaptation: Tibetan and Andean high-altitude natives. Proc. Natl. Acad. Sci. U. S. A. 104(Suppl. 1), 8655-8660

6. Beall, C. M. (2006) Andean, Tibetan, and Ethiopian patterns of adaptation to high-altitude hypoxia. Integr. Comp. Biol. 46, 18-24

7. Simonson, T. S., Yang, Y., Huff, C. D., Yun, H., Qin, G., Witherspoon, D. J., Bai, Z., Lorenzo, F. R., Xing, J., Jorde, L. B., Prchal, J. T., and Ge, R. (2010) Genetic evidence for highaltitude adaptation in Tibet. Science 329, 72-75

8. Bigham, A., Bauchet, M., Pinto, D., Mao, X., Akey, J. M., Mei, R., Scherer, S. W., Julian, C. G., Wilson, M. J., Lopez, H. D., Brutsaert, T., Parra, E. J., Moore, L. G., and Shriver, M. D. (2010) Identifying signatures of natural selection in Tibetan and Andean populations using dense genome scan data. PLoS Genet. 6, e1001116

9. Grocott, M., and Montgomery, H. (2008) Genetophysiology: using genetic strategies to explore hypoxic adaptation. High Alt. Med. Biol. 9, 123-129

10. Martin, D. S., Levett, D. Z., Grocott, M. P., and Montgomery, H. E. (2010) Variation in human performance in the hypoxic mountain environment. Exp. Physiol. 95, 463-470

11. Koumenis, C., and Wouters, B. G. (2006) "Translating" tumor hypoxia: unfolded protein response (UPR)-dependent and UPR-independent pathways. Mol. Cancer Res. 4, 423-436

12. Liu, L., Cash, T. P., Jones, R. G., Keith, B., Thompson, C. B., and Simon, M. C. (2006) Hypoxia-induced energy stress regulates mRNA translation and cell growth. Mol. Cell 21, 521-531

13. Brugarolas, J., Lei, K., Hurley, R. L., Manning, B. D., Reiling, J. H., Hafen, E., Witters, L. A., Ellisen, L. W., and Kaelin, W. G., Jr. (2004) Regulation of mTOR function in response to hypoxia by REDD1 and the TSC1/TSC2 tumor suppressor complex. Genes Dev. 18, 2893-2904

14. Chaudhary, P., Suryakumar, G., Prasad, R., Singh, S. N., Ali, S., and Ilavazhagan, G. (2012) Chronic hypobaric hypoxia mediated skeletal muscle atrophy: role of ubiquitin-proteasome pathway and calpains. Mol. Cell. Biochem. 364, 101-113

15. Chaillou, T., Koulmann, N., Simler, N., Meunier, A., Serrurier, B., Chapot, R., Peinnequin, A., Beaudry, M., and Bigard, X. (2012) Hypoxia transiently affects skeletal muscle hypertrophy in a functional overload model. Am. J. Physiol. 302, R643-R654

16. Chaillou, T., Koulmann, N., Meunier, A., Malgoyre, A., Serrurier, B., Beaudry, M., and Bigard, X. (2013) Effect of hypoxia exposure on the phenotypic adaptation in remodelling skeletal muscle submitted to functional overload. [E-pub ahead of print] Acta Physiol. (Oxf.) doi:10.1111/apha.12110

17. Favier, F. B., Costes, F., Defour, A., Bonnefoy, R., Lefai, E., Bauge, S., Peinnequin, A., Benoit, H., and Freyssenet, D. (2010) Downregulation of Akt/mammalian target of rapamycin pathway in skeletal muscle is associated with increased REDD1 expression in response to chronic hypoxia. Am. J. Physiol. 298, R1659-R1666

18. Bodine, S. C., Latres, E., Baumhueter, S., Lai, V. K., Nunez, L., Clarke, B. A., Poueymirou, W. T., Panaro, F. J., Na, E., Dharmarajan, K., Pan, Z. Q., Valenzuela, D. M., DeChiara, T. M., Stitt, T. N., Yancopoulos, G. D., and Glass, D. J. (2001) Identification of ubiquitin ligases required for skeletal muscle atrophy. Science 294, 1704-1708

19. Bonaldo, P., and Sandri, M. (2013) Cellular and molecular mechanisms of muscle atrophy. Dis. Models Mech. 6, 25-39

20. Tanida, I. (2011) Autophagosome formation and molecular mechanism of autophagy. Antioxid. Redox Signal. 14, 2201-2214

21. Ichimura, Y., and Komatsu, M. (2010) Selective degradation of p62 by autophagy. Semin. Immunopathol. 32, 431-436

22. Martinelli, M., Winterhalder, R., Cerretelli, P., Howald, H., and Hoppeler, H. (1990) Muscle lipofuscin content and satellite cell volume is increased after high altitude exposure in humans. Experientia 46, 672-676 
23. Westerterp-Plantenga, M. S., Westerterp, K. R., Rubbens, M., Verwegen, C. R., Richelet, J. P., and Gardette, B. (1999) Appetite at "high altitude" [Operation Everest III (Comex-'97)]: a simulated ascent of Mount Everest. J. Appl. Physiol. 87, 391-399

24. Nicholson, A. N., Smith, P. A., Stone, B. M., Bradwell, A. R., and Coote, J. H. (1988) Altitude insomnia: studies during an expedition to the Himalayas. Sleep 11, 354-361

25. D'Hulst, G., Jamart, C., Van Thienen, R., Hespel, P., Francaux, M., and Deldicque, L. (2013) Effect of acute environmental hypoxia on protein metabolism in human skeletal muscle. Acta Physiol. (Oxf.) 208, 251-264

26. Ferrari, M., Mottola, L., and Quaresima, V. (2004) Principles, techniques, and limitations of near infrared spectroscopy. Can. J. Appl. Physiol. 29, 463-487

27. Deldicque, L., De Bock, K., Maris, M., Ramaekers, M., Nielens, H., Francaux, M., and Hespel, P. (2010) Increased p70s6k phosphorylation during intake of a protein-carbohydrate drink following resistance exercise in the fasted state. Eur. J. Appl. Physiol. 108, 791-800

28. Jamart, C., Raymackers, J. M., Li, A. G., Deldicque, L., and Francaux, M. (2011) Prevention of muscle disuse atrophy by MG132 proteasome inhibitor. Muscle Nerve 43, 708-716

29. Vincent, B., Windelinckx, A., Nielens, H., Ramaekers, M., Van Leemputte, M., Hespel, P., and Thomis, M. A. (2010) Protective role of $\alpha$-actinin- 3 in the response to an acute eccentric exercise bout. J. Appl. Physiol. 109, 564-573

30. Vandesompele, J., De Preter, K., Pattyn, F., Poppe, B., Van Roy, N., De Paepe, A., and Speleman, F. (2002) Accurate normalization of real-time quantitative RT-PCR data by geometric averaging of multiple internal control genes. Genome Biol. 3, RESEARCH0034

31. Bouchard, C., Perusse, L., and Leblanc, C. (1990) Using MZ twins in experimental research to test for the presence of a genotype-environment interaction effect. Acta Genet. Med. Gemellol. (Roma) 39:85-89

32. Koumenis, C., Bi, M., Ye, J., Feldman, D., and Koong, A. C. (2007) Hypoxia and the unfolded protein response. Methods Enzymol. 435, 275-293

33. Barth, S., Glick, D., and Macleod, K. F. (2010) Autophagy: assays and artifacts. J. Pathol. 221, 117-124

34. Bjorkoy, G., Lamark, T., Pankiv, S., Overvatn, A., Brech, A., and Johansen, T. (2009) Monitoring autophagic degradation of p62/SQSTM1. Methods Enzymol. 452, 181-197

35. Zhang, J., and Ney, P. A. (2009) Role of BNIP3 and NIX in cell death, autophagy, and mitophagy. Cell Death Differ. 16, 939-946

36. Stitt, T. N., Drujan, D., Clarke, B. A., Panaro, F., Timofeyva, Y., Kline, W. O., Gonzalez, M., Yancopoulos, G. D., and Glass, D. J. (2004) The IGF-1/PI3K/Akt pathway prevents expression of muscle atrophy-induced ubiquitin ligases by inhibiting FOXO transcription factors. Mol. Cell 14, 395-403

37. Baserga, R. (1991) Growth regulation of the PCNA gene. J. Cell Sci. 98(Pt. 4), 433-436

38. Hoppeler, H., Kleinert, E., Schlegel, C., Claassen, H., Howald, H., Kayar, S. R., and Cerretelli, P. (1990) Morphological adaptations of human skeletal muscle to chronic hypoxia. Int. J. Sports Med. 11(Suppl. 1):S3-S9

39. Hoppeler, H., and Vogt, M. (2001) Muscle tissue adaptations to hypoxia. J. Exp. Biol. 204, 3133-3139

40. Schols, A. M., Broekhuizen, R., Weling-Scheepers, C. A., and Wouters, E. F. (2005) Body composition and mortality in chronic obstructive pulmonary disease. Am. J. Clin. Nutr. 82, 53-59

41. Giordano, F. J. (2005) Oxygen, oxidative stress, hypoxia, and heart failure. J. Clin. Invest. 115, 500-508

42. Klionsky, D. J., Abeliovich, H., Agostinis, P., Agrawal, D. K., Aliev, G., Askew, D. S., Baba, M., Baehrecke, E. H., Bahr, B. A., Ballabio, A., Bamber, B. A., Bassham, D. C., Bergamini, E., Bi, X., Biard-Piechaczyk, M., Blum, J. S., Bredesen, D. E., Brodsky, J. L., Brumell, J. H., Brunk, U. T., Bursch, W., Camougrand, N., Cebollero, E., Cecconi, F., Chen, Y., Chin, L. S., Choi, A., Chu, C. T., Chung, J., Clarke, P. G., Clark, R. S., Clarke, S. G., Clave, C., Cleveland, J. L., Codogno, P., Colombo, M. I., Coto-Montes, A., Cregg, J. M., Cuervo, A. M., Debnath, J., Demarchi, F., Dennis, P. B., Dennis, P. A., Deretic, V., Devenish, R. J., Di, S. F., Dice, J. F., Difiglia, M., Dinesh-Kumar, S., Distelhorst, C. W., Djavaheri-Mergny, M., Dorsey, F. C., Droge, W., Dron, M., Dunn, W. A., Jr., Duszenko, M., Eissa, N. T., Elazar, Z., Esclatine,
A., Eskelinen, E. L., Fesus, L., Finley, K. D., Fuentes, J. M., Fueyo, J., Fujisaki, K., Galliot, B., Gao, F. B., Gewirtz, D. A., Gibson, S. B., Gohla, A., Goldberg, A. L., Gonzalez, R., Gonzalez-Estevez, C., Gorski, S., Gottlieb, R. A., Haussinger, D., He, Y. W., Heidenreich, K., Hill, J. A., Hoyer-Hansen, M., Hu, X., Huang, W. P., Iwasaki, A., Jaattela, M., Jackson, W. T., Jiang, X., Jin, S., Johansen, T., Jung, J. U., Kadowaki, M., Kang, C., Kelekar, A., Kessel, D. H., Kiel, J. A., Kim, H. P., Kimchi, A., Kinsella, T. J., Kiselyov, K., Kitamoto, K., Knecht, E., Komatsu, M., Kominami, E., Kondo, S., Kovacs, A. L., Kroemer, G., Kuan, C. Y., Kumar, R., Kundu, M., Landry, J., Laporte, M., Le, W., Lei, H. Y., Lenardo, M. J., Levine, B., Lieberman, A., Lim, K. L., Lin, F. C., Liou, W., Liu, L. F., Lopez-Berestein, G., Lopez-Otin, C., Lu, B., Macleod, K. F., Malorni, W., Martinet, W., Matsuoka, K., Mautner, J., Meijer, A. J., Melendez, A., Michels, P., Miotto, G., Mistiaen, W. P., Mizushima, N., Mograbi, B., Monastyrska, I., Moore, M. N., Moreira, P. I., Moriyasu, Y., Motyl, T., Munz, C., Murphy, L. O., Naqvi, N. I., Neufeld, T. P., Nishino, I., Nixon, R. A., Noda, T., Nurnberg, B., Ogawa, M., Oleinick, N. L., Olsen, L. J., Ozpolat, B., Paglin, S., Palmer, G. E., Papassideri, I., Parkes, M., Perlmutter, D. H., Perry, G., Piacentini, M., Pinkas-Kramarski, R., Prescott, M., Proikas-Cezanne, T., Raben, N., Rami, A., Reggiori, F., Rohrer, B., Rubinsztein, D. C., Ryan, K. M., Sadoshima, J., Sakagami, H., Sakai, Y., Sandri, M., Sasakawa, C., Sass, M., Schneider, C., Seglen, P. O., Seleverstov, O., Settleman, J., Shacka, J. J., Shapiro, I. M., Sibirny, A., Silva-Zacarin, E. C., Simon, H. U., Simone, C., Simonsen, A., Smith, M. A., SpanelBorowski, K., Srinivas, V., Steeves, M., Stenmark, H., Stromhaug, P. E., Subauste, C. S., Sugimoto, S., Sulzer, D., Suzuki, T., Swanson, M. S., Tabas, I., Takeshita, F., Talbot, N. J., Talloczy, Z., Tanaka, K., Tanaka, K., TanidaI., Taylor, G. S., Taylor, J. P., Terman, A., Tettamanti, G., Thompson, C. B., Thumm, M., Tolkovsky, A. M., Tooze, S. A., Truant, R., Tumanovska, L. V., Uchiyama, Y., Ueno, T., Uzcategui, N. L., van der Klei, I., Vaquero, E. C., Vellai, T., Vogel, M. W., Wang, H. G., Webster, P., Wiley, J. W., Xi, Z., Xiao, G., Yahalom, J., Yang, J. M., Yap, G., Yin, X. M., Yoshimori, T., Yu, L., Yue, Z., Yuzaki, M., Zabirnyk, O., Zheng, X., Zhu, X., and Deter, R. L. (2008) Guidelines for the use and interpretation of assays for monitoring autophagy in higher eukaryotes. Autophagy 4, 151-175

43. Jamart, C., Benoit, N., Raymackers, J. M., Kim, H. J., Kim, C. K., and Francaux, M. (2012) Autophagy-related and autophagyregulatory genes are induced in human muscle after ultraendurance exercise. Eur. J. Appl. Physiol. 112, 3173-3177

44. Mammucari, C., Milan, G., Romanello, V., Masiero, E., Rudolf, R., Del, P. P., Burden, S. J., Di, L. R., Sandri, C., Zhao, J., Goldberg, A. L., Schiaffino, S., and Sandri, M. (2007) FoxO3 controls autophagy in skeletal muscle in vivo. Cell Metab. 6, $458-471$

45. Chaudhary, P., Suryakumar, G., Prasad, R., Singh, S. N., Ali, S., and Ilavazhagan, G. (2012) Effect of acute hypobaric hypoxia on skeletal muscle protein turnover. Al Ameen J. Med. Sci. 5, 355-361

46. Zhao, J., Brault, J. J., Schild, A., Cao, P., Sandri, M., Schiaffino, S., Lecker, S. H., and Goldberg, A. L. (2007) FoxO3 coordinately activates protein degradation by the autophagic/lysosomal and proteasomal pathways in atrophying muscle cells. Cell Metab. 6, 472-483

47. Van Der Heide, L. P., Hoekman, M. F., and Smidt, M. P. (2004) The ins and outs of FoxO shuttling: mechanisms of FoxO translocation and transcriptional regulation. Biochem. J. 380, 297-309

48. Lacey, R. J., Cable, H. C., James, R. F., London, N. J., Scarpello, J. H., and Morgan, N. G. (1993) Concentration-dependent effects of adrenaline on the profile of insulin secretion from isolated human islets of Langerhans. J. Endocrinol. 138, 555-563

49. Arsham, A. M., Howell, J. J., and Simon, M. C. (2003) A novel hypoxia-inducible factor-independent hypoxic response regulating mammalian target of rapamycin and its targets. J. Biol. Chem. 278, 29655-29660

50. Preedy, V. R., Smith, D. M., and Sugden, P. H. (1985) The effects of 6 hours of hypoxia on protein synthesis in rat tissues in vivo and in vitro. Biochem. J. 228, 179-185

51. Preedy, V. R., and Sugden, P. H. (1989) The effects of fasting or hypoxia on rates of protein synthesis in vivo in subcellular fractions of rat heart and gastrocnemius muscle. Biochem. J. 257, $519-527$ 
52. Vigano, A., Ripamonti, M., De Palma, S., Capitanio, D., Vasso, M., Wait, R., Lundby, C., Cerretelli, P., and Gelfi, C. (2008) Proteins modulation in human skeletal muscle in the early phase of adaptation to hypobaric hypoxia. Proteomics 8, 46684679

53. Rennie, M.J., Babij, P., Sutton, J. R., Tonkins, W. J., Read, W. W., Ford, C., and Halliday, D. (1983) Effects of acute hypoxia on forearm leucine metabolism. Prog. Clin. Biol. Res. 136, 317-323

54. Etheridge, T., Atherton, P. J., Wilkinson, D., Selby, A., Rankin, D., Webborn, N., Smith, K., and Watt, P. W. (2011) Effects of hypoxia on muscle protein synthesis and anabolic signaling at rest and in response to acute resistance exercise. Am. J. Physiol. Endocrinol. Metab. 301, E697-E702

55. Imoberdorf, R., Garlick, P. J., McNurlan, M. A., Casella, G. A., Marini, J. C., Turgay, M., Bartsch, P., and Ballmer, P. E. (2006) Skeletal muscle protein synthesis after active or passive ascent to high altitude. Med. Sci. Sports Exerc. 38, 1082-1087

56. Egan, B., Carson, B. P., Garcia-Roves, P. M., Chibalin, A. V., Sarsfield, F. M., Barron, N., McCaffrey, N., Moyna, N. M., Zierath, J. R., and O'Gorman, D. J. (2010) Exercise intensitydependent regulation of peroxisome proliferator-activated receptor coactivator-1 mRNA abundance is associated with differential activation of upstream signalling kinases in human skeletal muscle. J. Physiol. 588, 1779-1790

57. Sriwijitkamol, A., Coletta, D. K., Wajcberg, E., Balbontin, G. B., Reyna, S. M., Barrientes, J., Eagan, P. A., Jenkinson, C. P., Cersosimo, E., DeFronzo, R. A., Sakamoto, K., and Musi, N. (2007) Effect of acute exercise on AMPK signaling in skeletal muscle of subjects with type 2 diabetes: a time-course and dose-response study. Diabetes 56, 836-848

58. Amirouche, A., Durieux, A. C., Banzet, S., Koulmann, N., Bonnefoy, R., Mouret, C., Bigard, X., Peinnequin, A., and
Freyssenet, D. (2009) Down-regulation of Akt/mammalian target of rapamycin signaling pathway in response to myostatin overexpression in skeletal muscle. Endocrinology 150, 286-294

59. Hayot, M., Rodriguez, J., Vernus, B., Carnac, G., Jean, E., Allen, D., Goret, L., Obert, P., Candau, R., and Bonnieu, A. (2011) Myostatin up-regulation is associated with the skeletal muscle response to hypoxic stimuli. Mol. Cell. Endocrinol. 332, 38-47

60. Thomis, M. A., Beunen, G. P., Maes, H. H., Blimkie, C. J., Van, L. M., Claessens, A. L., Marchal, G., Willems, E., and Vlietinck, R. F. (1998) Strength training: importance of genetic factors. Med. Sci. Sports Exerc. 30, 724-731

61. Schiaffino, S., Dyar, K. A., Ciciliot, S., Blaauw, B., and Sandri, M. (2013) Mechanisms regulating skeletal muscle growth and atrophy. FEBS J. 280, 4294-4314

62. Ciciliot, S., and Schiaffino, S. (2010) Regeneration of mammalian skeletal muscle. Basic mechanisms and clinical implications. Curr. Pharm. Des. 16, 906-914

63. Macaluso, F., and Myburgh, K. H. (2012) Current evidence that exercise can increase the number of adult stem cells. J. Muscle Res. Cell Motil. 33, 187-198

64. Csete, M., Walikonis, J., Slawny, N., Wei, Y., Korsnes, S., Doyle, J. C., and Wold, B. (2001) Oxygen-mediated regulation of skeletal muscle satellite cell proliferation and adipogenesis in culture. J. Cell. Physiol. 189, 189-196

65. Koning, M., Werker, P. M., van Luyn, M. J., and Harmsen, M. C. (2011) Hypoxia promotes proliferation of human myogenic satellite cells: a potential benefactor in tissue engineering of skeletal muscle. Tissue Eng. A 17, 1747-1758

Received for publication September 9, 2013. Accepted for publication October 24, 2013. 